\title{
Three-dimensional motion analysis of the cervical spine for comparison of anterior cervical decompression and fusion versus artificial disc replacement in 17 patients
}

\author{
Clinical article
}

\author{
Colin P. McDonald, Ph.D., ${ }^{1}$ Victor Chang, M.D., ${ }^{2}$ Michael McDonald, B.S., ${ }^{1}$ \\ Nicole Ramo, B.S., ${ }^{1}$ Michael J. Bey, Ph.D., ${ }^{1}$ And Stephen Bartol, M.D. ${ }^{1}$ \\ ${ }^{1}$ Department of Orthopedics, Herrick Davis Motion Analysis Laboratory, and ${ }^{2}$ Department of Neurosurgery, \\ Henry Ford Health System, Detroit, Michigan
}

\begin{abstract}
Object. Cervical arthroplasty with an artificial disc (AD) has emerged as an alternative to anterior cervical discectomy and fusion (ACDF) for the management of cervical spondylosis. This study aims to provide 3D motion analysis data comparing patients after $\mathrm{ACDF}$ and $\mathrm{AD}$ replacement.

Methods. Ten patients who underwent C5-6 ACDF and 7 who underwent C5-6 AD replacement were enrolled. Using biplanar fluoroscopy and a model-based track technique (accurate up to $0.6 \mathrm{~mm}$ and $0.6^{\circ}$ ), motion analysis of axial rotation and flexion-extension of the neck was performed. Three nonoperative segments (C3-4, C4-5, and C6-7) were assessed for both intervertebral rotation (coronal, sagittal, and axial planes) and facet shear (anteroposterior and mediolateral).

Results. There was no difference in total neck motion comparing ACDF and AD replacement for neck extension $\left(43.3^{\circ} \pm 10.2^{\circ}\right.$ vs $\left.44.3^{\circ} \pm 12.6^{\circ}, \mathrm{p}=0.866\right)$ and rotation $\left(36.0^{\circ} \pm 6.5^{\circ}\right.$ vs $\left.38.2^{\circ} \pm 9.3^{\circ}, \mathrm{p}=0.576\right)$. For extension, when measured as a percentage of total neck motion, there was a greater amount of rotation at the nonoperated segments in the ACDF group than in the AD group $(\mathrm{p}=0.003)$. When comparing specific motion segments, greater normalized rotation was seen in the ACDF group at $\mathrm{C} 3-4(33.2 \% \pm 4.9 \%$ vs $26.8 \% \pm 6.6 \%, \mathrm{p}=0.036)$ and $\mathrm{C} 6-7(28.5 \% \pm 6.7 \%$ vs $20.5 \% \pm 5.5 \%, \mathrm{p}=0.009)$ but not at $\mathrm{C} 4-5(33.5 \% \pm 6.4 \%$ vs $31.8 \% \pm 4.0 \%, \mathrm{p}=0.562)$. For neck rotation, greater rotation was observed at the nonoperative segments in the ACDF group than in the AD group $(\mathrm{p}=0.024)$, but the differences between individual segments did not reach significance $(\mathrm{p} \geq 0.146)$. Increased mediolateral facet shear was seen on neck extension with ACDF versus AD replacement $(\mathrm{p}=0.008)$. Comparing each segment, C3-4 $(0.9 \pm 0.5$ $\mathrm{mm}$ vs $0.4 \pm 0.1 \mathrm{~mm}, \mathrm{p}=0.039)$ and $\mathrm{C} 4-5(1.0 \pm 0.4 \mathrm{~mm}$ vs $0.5 \pm 0.2 \mathrm{~mm}, \mathrm{p}=0.022)$ showed increased shear while C6-7 $(1.0 \pm 0.4 \mathrm{~mm}$ vs $1.0 \pm 0.5 \mathrm{~mm}, \mathrm{p}=0.767)$ did not.

Conclusions. This study illustrates increased motion at nonoperative segments in patients who have undergone ACDF compared with those who have undergone AD replacement. Further studies will be required to examine whether these changes contribute to adjacent-segment disease. (http://thejns.org/doi/abs/10.3171/2013.11 SPINE13392)
\end{abstract}

Key Words — artificial disc $\quad$ • cervical fusion $\quad$ a adjacent-segment disease

A NTERIOR cervical decompression and fusion (ACDF) is the most common treatment for patients with cervical spine disorders, with the number of procedures increasing by $114 \%$ from 1998 to $2008 .{ }^{60} \mathrm{Nu}-$ merous clinical studies have demonstrated the successful

\footnotetext{
Abbreviations used in this paper: $\mathrm{ACDF}=$ anterior cervical decompression and fusion; $\mathrm{AD}=$ artificial disc; $\mathrm{AP}=$ anteroposterior; CASP = clinical adjacent-segment pathology; $\mathrm{ML}=$ mediolateral; RASP = radiographic adjacent-segment pathology; SI $=$ superoinferior.
}

long-term clinical outcome of anterior fusion. ${ }^{2,6,17,19,23,27,73}$ However, other studies have reported a high incidence of degeneration and subsequent symptoms at the adjacent vertebral segments following surgery, with degenerative changes seen in $25 \%-92 \%$ of patients and clinical symptoms presenting in $14 \%-26 \%$ of patients. ${ }^{15,22,28,37,41,62} \mathrm{Cer}-$ vical fusion has been reported to alter adjacent-segment motion, load, and intradiscal pressures, $3,14,36,46,59$ and this

This article contains some figures that are displayed in color online but in black-and-white in the print edition. 


\section{P. McDonald et al.}

is believed to induce degenerative changes in the adjacent segments. ${ }^{25}$ However, it remains unclear whether degenerative changes are the result of changes in the mechanical behavior of the cervical spine or simply a natural progression of the disease with aging.

Cervical arthroplasty with an artificial disc (AD) was designed as an alternative to cervical fusion, with the goal of preserving motion patterns at the implanted level and maintaining normal motion patterns in the adjacent segments. To date there have been several published reports of randomized controlled trials comparing ACDF with AD replacement with varying results. $4,21,35,48,64,70,71$ The results of these trials have shown that AD replacement has excellent outcomes and in some instances is superior to $\mathrm{ACDF}$ with lower reoperation rates as well as improved clinical outcomes. Biomechanical studies are important to better understand neck function postsurgery and may provide insight into the mechanical factors that contribute to a good or poor clinical outcome. Unfortunately, there are many gaps in our understanding of the biomechanics of the cervical spine in patients treated with cervical arthroplasty. Although it has been well documented that cervical arthroplasty results in greater motion at the surgical level than fusion, ${ }^{18,34,36,45,53,58,63}$ adjacent-segment biomechanics are less clear. Some studies have reported greater adjacent-segment motion in patients who have undergone fusion, ${ }^{18,45,72}$ while others have reported no difference between these treatment groups. ${ }^{34,36,58}$ One potential reason for the discrepancy in findings between previous studies may be due to the techniques used. Previous studies investigating cervical spine motion are often limited to a $2 \mathrm{D}$ analysis $\mathrm{s}^{18,34,39,43,45,53}$ or cadaveric simulations..$^{14,59}$ Although cadaveric simulations are ideal for measuring 3D motion patterns, they are not designed to reproduce the joint forces, muscle forces, and complex motion patterns associated with in vivo conditions. Two-dimensional analysis methods are well suited for measuring relatively planar movements, such as neck flexion and extension, but are highly susceptible to errors attributed to out-of-plane movement. This may also explain why in vivo studies comparing fusion and arthroplasty are typically isolated to neck flexion-extension motion activities, leaving a gap in our understanding of differences in biomechanics during axial neck rotation.

The mechanics of cervical arthroplasty in comparison with cervical fusion may be better understood using a validated $3 \mathrm{D}$ in vivo technique. The objective of this study was to compare in vivo, 3D, dynamic cervical spine kinematics between patients undergoing cervical arthroplasty and those undergoing cervical fusion. We hypothesized that adjacent-segment kinematics (in terms of vertebral rotation and articular facet translation) would be significantly greater in the patients who underwent surgical fusion.

\section{Methods}

\section{Clinical Features}

Following institutional review board approval and informed consent, 17 patients treated for cervical radicu- lopathy at C5-6 were included. All patients who showed no complications or evidence of pseudarthrosis (ACDF group), device failure (AD group), or heterotopic ossification (AD group) and who had undergone their surgery at least 12 months earlier were eligible for inclusion. In addition, all patients included in the study had no evidence of ongoing radiculopathy at the index level. Ten subjects underwent single-level ACDF and 7 subjects underwent single-level cervical arthroplasty with an AD.

\section{Motion Analysis}

Subjects were seated with their neck centered in a biplane X-ray system (Fig. 1). Biplane radiographs were acquired during 2 motion activities: neck extension and axial neck rotation. Three motion trials were acquired for each motion task. The biplane radiographs had a $23-\mathrm{cm}$ field of view and were acquired at $60 \mathrm{~Hz}$ for 2 seconds with the $x$-ray generators in pulsed mode $(70 \mathrm{kV}, 160 \mathrm{~mA})$.

Following testing, CT images of each subject's cervical spine were acquired (LightSpeed VCT, GE Medical Systems). Imaging parameters included a field of view of $130 \mathrm{~mm}$, a $512 \times 512$ acquisition matrix, and a voxel size of $0.25 \times 0.25 \times 0.625 \mathrm{~mm}$. The CT images of C-3 through C-7 were then segmented from surrounding bones and soft tissues using commercial software (Mimics 12.0, Materialise) and reconstructed to generate 3D bone models of each vertebra.

The 3D position and orientation of each cervical vertebra was determined from the biplane radiographs using a model-based tracking technique. ${ }^{5,47}$ This technique allowed for the independent determination of the 3D position and orientation of 1 vertebra relative to an adjacent vertebra for all frames of each trial and is accurate to within $0.6 \mathrm{~mm}$ and $0.6^{\circ} .{ }^{47}$

An anatomical coordinate system was created for each vertebra using custom software (Fig. 2 left). ${ }^{66}$ The vertebral body coordinate system was defined by 3 orthogonal vectors oriented in the anteroposterior (AP) direction (AP axis), mediolateral (ML) direction (ML axis), and superoinferior (SI) direction (SI axis). Similarly, anatomical coordinate systems were created for each articular facet using anatomical landmarks and vector crossproducts (Fig. 2 right). ${ }^{40,42,44}$ The $\mathrm{x}$ axis was oriented in the anterosuperior direction, the $\mathrm{y}$ axis was oriented in the lateral direction, and the $\mathrm{z}$ axis was oriented in the posterosuperior direction (Fig. 2 right). Outcome measures included vertebral rotation, facet translation, and estimated intervertebral disc height and were calculated based on the position and orientation data determined from biplane radiographs (Figs. 3 and 4). Vertebral rotations, facet translations, and estimated intervertebral disc height were calculated for the operative segment (C5-6), the adjacent segments (C4-5 and C6-7), and a remote segment (C3-4). Vertebral rotations were quantified using a technique described by Panjabi et al. ${ }^{51}$ As an additional outcome measure, vertebral rotation was also normalized as a percentage of the total subaxial neck rotation. Total subaxial neck rotation was defined as the full rotation of the C-3 vertebra with respect to the C-7 vertebra for each motion task. To describe facet translations, AP sliding was defined as translation of the inferior 

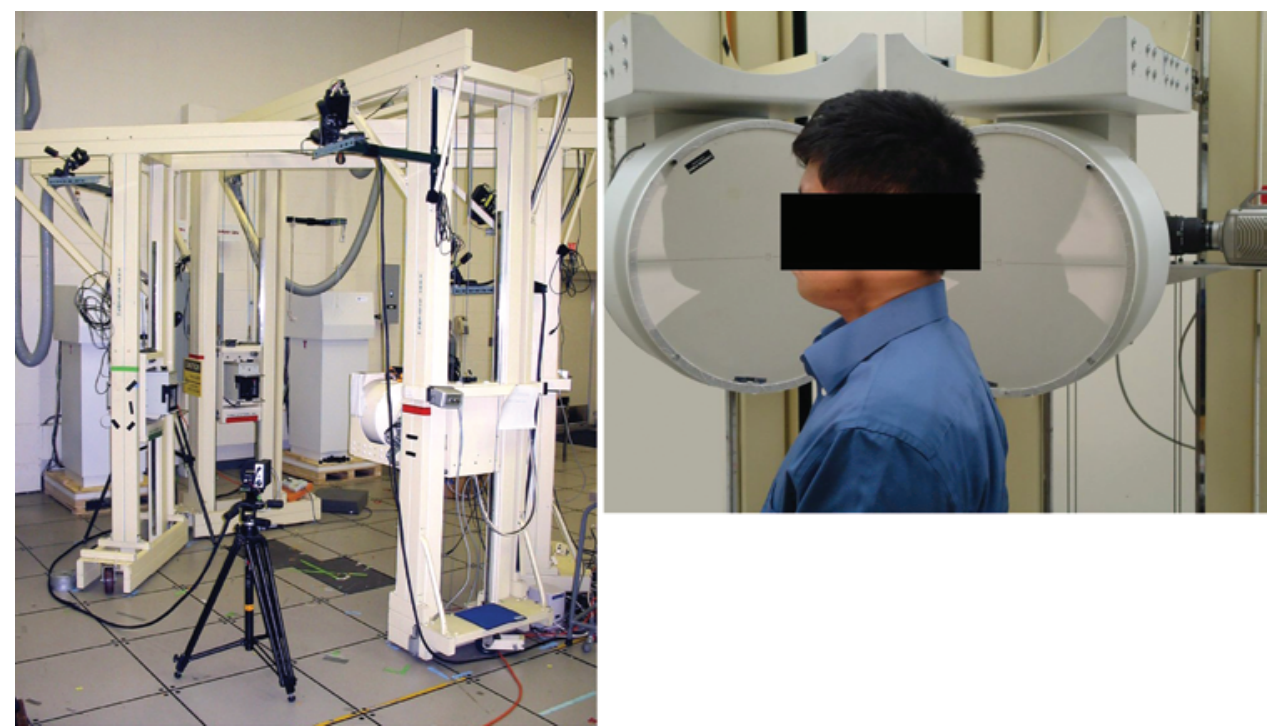

FIG. 1. Left: Photograph of the biplane x-ray system used for this study. Right: Photograph of a subject sitting within the field of view of both $x$-ray cameras for testing.

articular facet along the $\mathrm{x}$ axis of the adjacent superior articular facet, and ML shear was defined as translation of the inferior articular facet along the y axis of the adjacent superior articular facet (Fig. 2 right). Facet translation was calculated as the average translation between the left and right facets for each motion segment. Estimated disc height was calculated as the average endplate-to-endplate distance between adjacent vertebrae.

\section{Statistical Analysis}

Differences in vertebral rotation, normalized vertebral rotation, facet translation, and estimated intervertebral disc height were compared between the fusion group and arthroplasty group. At the operative segment (C5-6), differences between groups were assessed using individual t-tests. At the nonoperative segments (C3-4, C4-5, and C6-7), differences between groups were assessed using 2-way ANOVA, with surgical treatment and vertebral level being the independent variables. Vertebral rotation, normalized vertebral rotation, facet translation, and es-
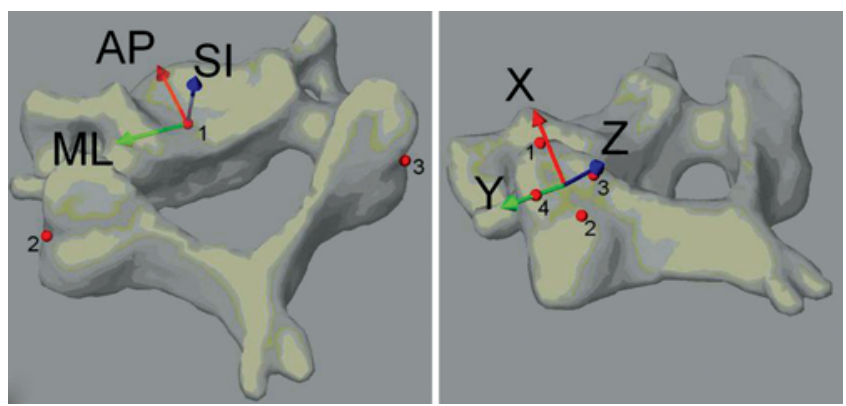

Fig. 2. An anatomical coordinate system was defined for the vertebral body and each articular facet. Left: The vertebral body coordinate system was defined by 3 anatomical landmarks: the center of the vertebral body (1), and the centers of the left (2) and right (3) lateral masses. Right: Each articular facet coordinate system was defined by 4 anatomical landmarks: the anterosuperior (1), posteroinferior (2), medial (3), and lateral (4) aspects of each facet. X, Y, and Z denote the axes. timated intervertebral disc height were also compared across all motion segments (both operative and nonoperative) using a 1-way analysis of variance for each group, with vertebral level being the independent variable. The translational components of facet translation were compared for each group using a paired t-test. Significance was set at $\mathrm{p}<0.05$.

\section{Results}

A total of 17 patients were included in the study. Ten patients underwent C5-6 ACDF, while 7 patients underwent C5-6 AD replacement. The mean age for the ACDF group was $48 \pm 10.8$ years, and the mean age of the AD group was $47 \pm 7.0$ years with no statistical difference between the groups $(\mathrm{p}=0.83)$. The mean postoperative period at time of enrollment was $24.1 \pm 7.4$ months for the fusion group and $22.0 \pm 3.3$ months for the arthroplasty group with no statistical difference between the groups $(\mathrm{p}=0.50)$.

\section{Vertebral Motion Between Groups in Neck Extension}

During the neck extension motion task, total lowerneck rotation was $43.3^{\circ} \pm 10.2^{\circ}$ in the ACDF group and $44.3^{\circ} \pm 12.6^{\circ}$ in the AD group $(\mathrm{p}=0.866)$. When comparing vertebral rotation between groups (Fig. 5), significant differences were found at the operative segment (C5-6), with vertebral rotation in the AD group $\left(8.8^{\circ} \pm 3.9^{\circ}\right)$ being significantly greater than in the ACDF group $\left(2.8^{\circ} \pm\right.$ $\left.1.2^{\circ}, \mathrm{p}=0.002\right)$. Although there was a trend for greater vertebral rotation in the ACDF group at the nonoperative segments (C3-4, C4-5, and C6-7), these differences were not statistically significant $(\mathrm{p}=0.093$, Fig. 5). Isolating differences in vertebral rotation by motion segment, differences between the ACDF group and AD group were most apparent at C6-7 $\left(12.4^{\circ} \pm 4.0^{\circ}\right.$ vs $9.2^{\circ} \pm 4.2^{\circ}, \mathrm{p}=$ $0.139)$ and least apparent at $\mathrm{C} 4-5\left(14.9^{\circ} \pm 5.9^{\circ}\right.$ vs $13.9^{\circ} \pm$ $\left.3.4^{\circ}, \mathrm{p}=0.711\right)$. Differences in vertebral motion between 

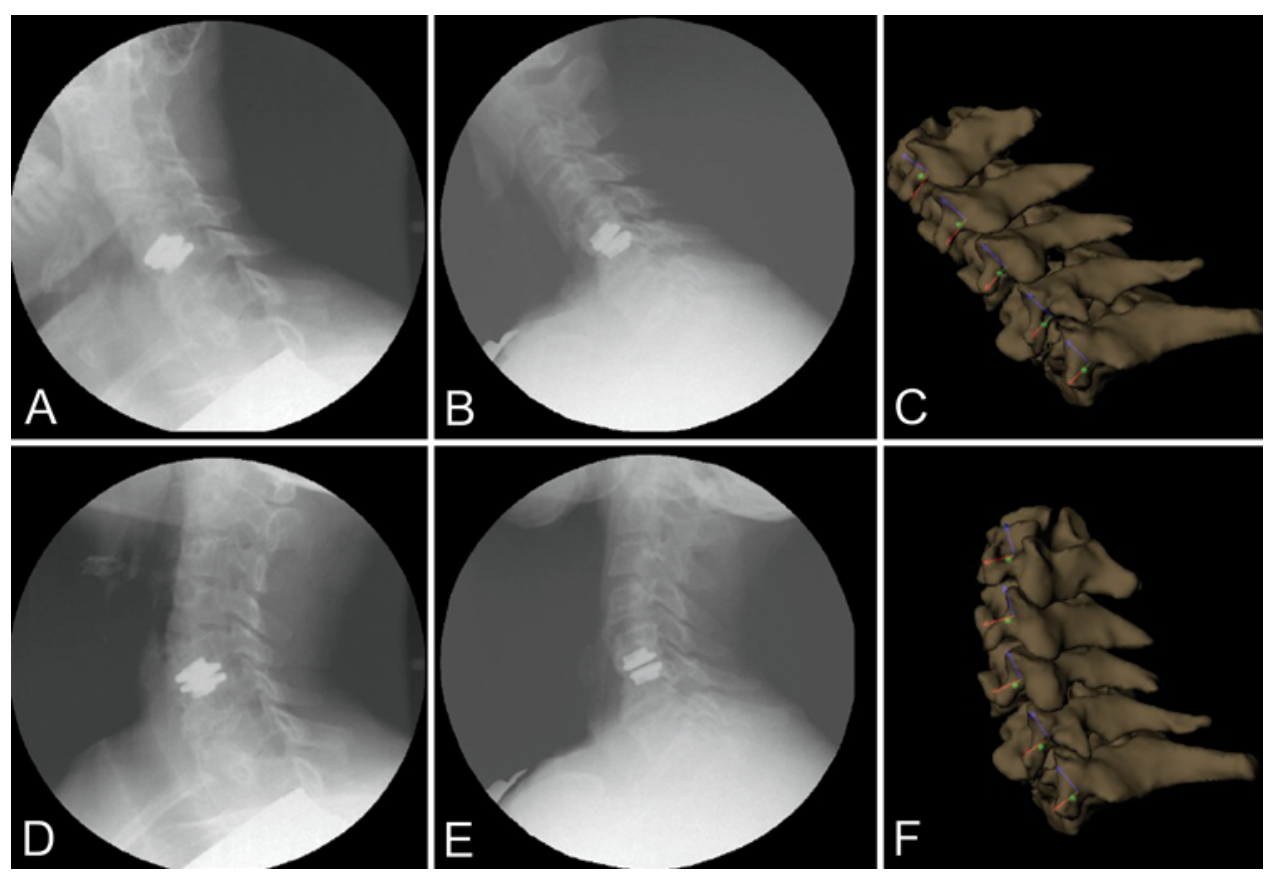

FIG. 3. Illustration of marker-less tracking and motion analysis. A and B: Oblique radiographs obtained in a patient at full flexion who underwent AD replacement. C: The 3D computer model generated after tracking, which is used for kinematic measurements. D and E: Oblique radiographs obtained in the same patient at full extension. F: The 3D computer model.

groups were more pronounced when evaluating vertebral rotations as a percentage of total lower-neck rotation (Fig. 6). Normalized vertebral rotation at C5-6 in the arthroplasty group $(19.7 \% \pm 6.2 \%)$ was significantly greater than in the ACDF group $(6.8 \% \pm 3.3 \%, \mathrm{p}<0.001)$. At the nonoperative segments, there was significantly greater motion in the ACDF group than in the AD group ( $\mathrm{p}=$ 0.003 ). Isolating differences by motion segment, normalized vertebral rotation in the ACDF group was significantly greater than the AD group at C3-4 (33.2\% $\pm 4.9 \%$ vs $26.8 \% \pm 6.6 \%, \mathrm{p}=0.036)$ and $\mathrm{C} 6-7(28.5 \% \pm 6.7 \%$ vs $20.5 \% \pm 5.5 \%, \mathrm{p}=0.009)$, but not at $\mathrm{C} 4-5(33.5 \% \pm 6.4 \%$ vs $31.8 \% \pm 4.0 \%, \mathrm{p}=0.562$ ).

\section{Vertebral Motion Between Groups in Axial Neck Rotation}

During the axial neck rotation motion task, total lower-neck rotation was $36.0^{\circ} \pm 6.5^{\circ}$ in the ACDF group and $38.2^{\circ} \pm 9.3^{\circ}$ in the AD group $(\mathrm{p}=0.576)$. When com- paring vertebral rotation between groups (Fig. 7), significant differences were found at $\mathrm{C} 5-6$, with vertebral rotation in the $\mathrm{AD}$ group $\left(7.2^{\circ} \pm 5.3^{\circ}\right)$ being significantly greater than in the ACDF group $\left(2.4^{\circ} \pm 1.2^{\circ}, \mathrm{p}=0.035\right)$. Vertebral rotation at the nonoperative segments (C3-4, C4-5, and C6-7) was greater in the ACDF group, but these differences were not significant $(p=0.104)$. Isolating differences in vertebral rotation by motion segment, differences between the ACDF group and AD group were most apparent at $\mathrm{C} 3-4\left(12.5^{\circ} \pm 2.7^{\circ}\right.$ vs $10.7^{\circ} \pm 1.6^{\circ}, \mathrm{p}=$ $0.235)$ and least apparent at $\mathrm{C} 4-5\left(13.6^{\circ} \pm 3.4^{\circ}\right.$ vs $12.6^{\circ} \pm$ $\left.2.5^{\circ}, \mathrm{p}=0.511\right)$. Differences in vertebral motion between groups were again more pronounced when evaluating normalized vertebral rotation (Fig. 8). Normalized vertebral rotation at $\mathrm{C} 5-6$ in the AD group $(17.2 \% \pm 9.1 \%)$ was significantly greater than in the ACDF group $(6.7 \%$ $\pm 2.6 \%, p=0.004)$. At the nonoperative segments, there was significantly greater motion in the ACDF group than
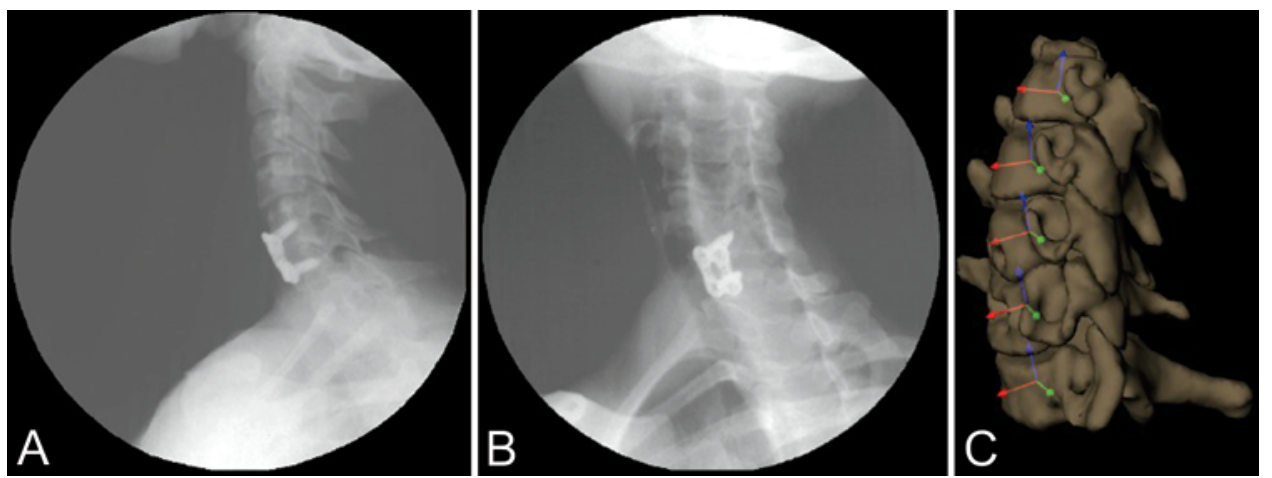

FIG. 4. An example of an ACDF patient's motion study at the fully extended position. A and B: Oblique radiographs obtained by the x-ray cameras. C: The 3D computer model generated after tracking, which is used for kinematic measurements. 


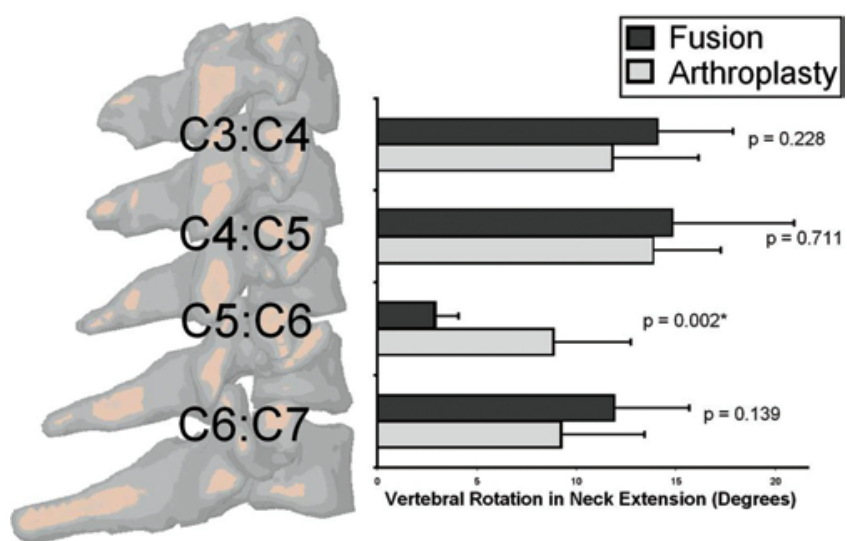

FIG. 5. Vertebral rotation is shown for the neck extension motion task. Vertebral rotation was greater in the AD group at $\mathrm{C5}-6$. There were differences in motion between groups at C3-4, C4-5, and C6-7, but these did not reach statistical significance.

in the $\mathrm{AD}$ group $(\mathrm{p}=0.024)$. However, there were no significant differences at any nonoperative segment when differences between groups were isolated by motion segment $(\mathrm{p} \geq 0.146)$.

\section{Vertebral Rotation Across Segments}

Comparing vertebral motion across both operative and nonoperative segments, C5-6 rotation was significantly less in the fusion group than in any of the nonoperative segments for both motion tasks $(\mathrm{p}<0.001)$. Rotation at $\mathrm{C} 5-6$ for the $\mathrm{ACDF}$ group ranged from $1.3^{\circ}$ to $5.1^{\circ}$ during neck extension and from $0.7^{\circ}$ to $4.3^{\circ}$ during axial neck rotation. For the $\mathrm{AD}$ group, there were no significant differences between C5-6 and either C3-4 or C6-7 (p $>0.142$ ). However, C5-6 rotation was significantly less than $\mathrm{C} 4-5$ rotation for both neck extension $\left(8.8^{\circ} \pm 3.9^{\circ}\right.$ vs $\left.13.9^{\circ} \pm 3.4^{\circ}, \mathrm{p}=0.027\right)$ and axial neck rotation $\left(7.2^{\circ} \pm\right.$ $5.3^{\circ}$ vs $12.6^{\circ} \pm 2.5^{\circ}, p=0.012$ ). Rotation at $\mathrm{C} 5-6$ for the $\mathrm{AD}$ group ranged from $4.5^{\circ}$ to $14.0^{\circ}$ during neck extension and from $2.3^{\circ}$ to $14.2^{\circ}$ during axial neck rotation.

\section{Facet Translation Between Groups}

For both motion tasks, facet translation in the AP slid-
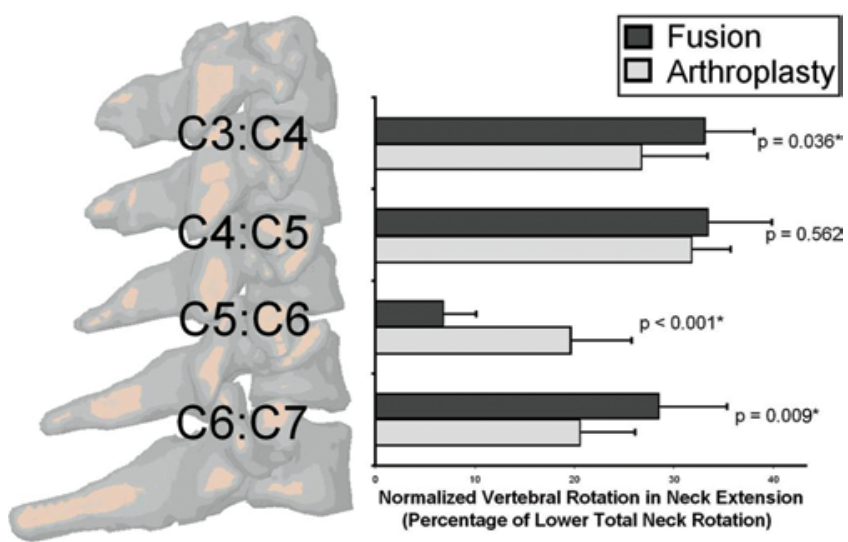

Fıg. 6. Normalized vertebral rotation is shown for the neck extension motion task. Normalized vertebral rotation was greater in the $A D$ group at $\mathrm{C5}-6$, and greater in the ACDF group at C3-4 and C6-7.

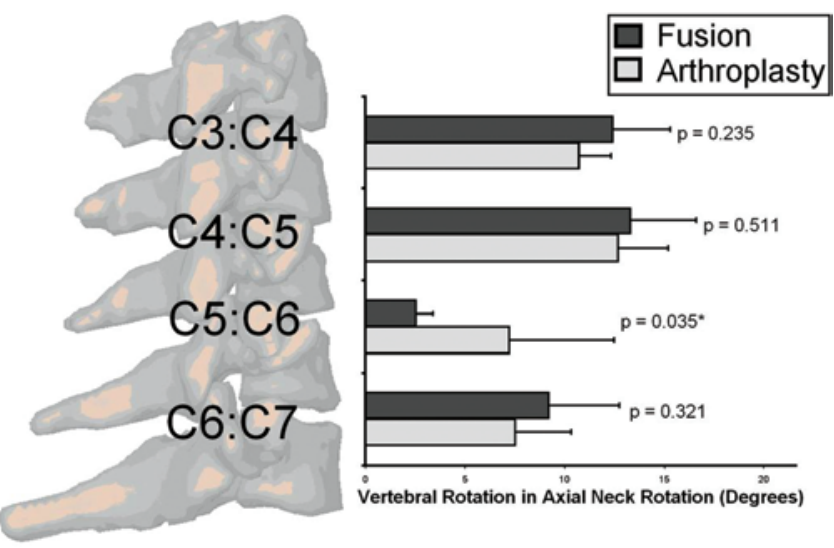

Fig. 7. Vertebral rotation is shown for the axial neck rotation motion task. Vertebral rotation was greater in the arthroplasty group at C5-6. There were no significant differences in motion between groups at C3-4, C4-5, and C6-7.

ing direction was greater than in the ML shear direction ( $<<0.001$, Figs. 9 and 10). Facet translation exhibited significantly greater ML shear during axial neck rotation than during neck extension $(\mathrm{p}<0.001)$. Comparing differences between groups, facet translation at C5-6 was greater in the $\mathrm{AD}$ group than the ACDF group, although this difference was only significant in the AP sliding direction $(\mathrm{p}<$ 0.001 for neck extension, $p=0.045$ for axial neck rotation). At the nonoperative segments, facet translation was greater in the ACDF group. However, these differences were only significant in the ML shear direction during neck extension $(\mathrm{p}=0.008)$. Isolating differences by motion segment, ML shear in the ACDF group was significantly greater than the arthroplasty group at C3-4 $(0.9 \pm 0.5 \mathrm{~mm}$ vs $0.4 \pm 0.1 \mathrm{~mm}$, $\mathrm{p}=0.039)$ and $\mathrm{C} 4-5(1.0 \pm 0.4 \mathrm{~mm}$ vs $0.5 \pm 0.2 \mathrm{~mm}, \mathrm{p}=$ $0.022)$, but not at $\mathrm{C} 6-7(1.0 \pm 0.4 \mathrm{~mm}$ vs $1.0 \pm 0.5 \mathrm{~mm}, \mathrm{p}$ $=0.767$ ).

\section{Intervertebral Disc Height Between Groups}

Intervertebral disc height at $\mathrm{C} 5-6$ in the $\mathrm{AD}$ group

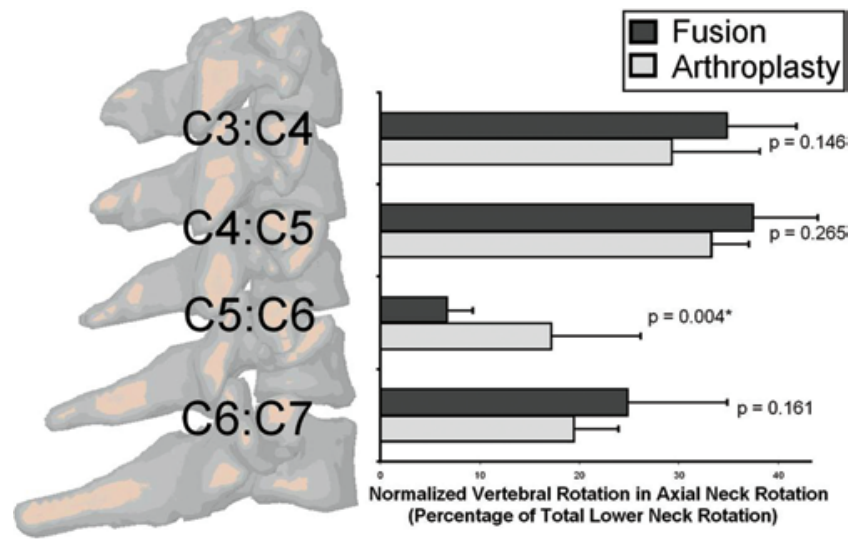

FIG. 8. Normalized vertebral rotation is shown for the axial neck rotation motion task. Normalized vertebral rotation was greater in the arthroplasty group at $\mathrm{C} 5-6$. Although differences in motion at the adjacent (C4-5 and $\mathrm{C} 6-7)$ and remote (C3-4) segments were more pronounced compared with vertebral rotation, there were again no significant differences between groups. 

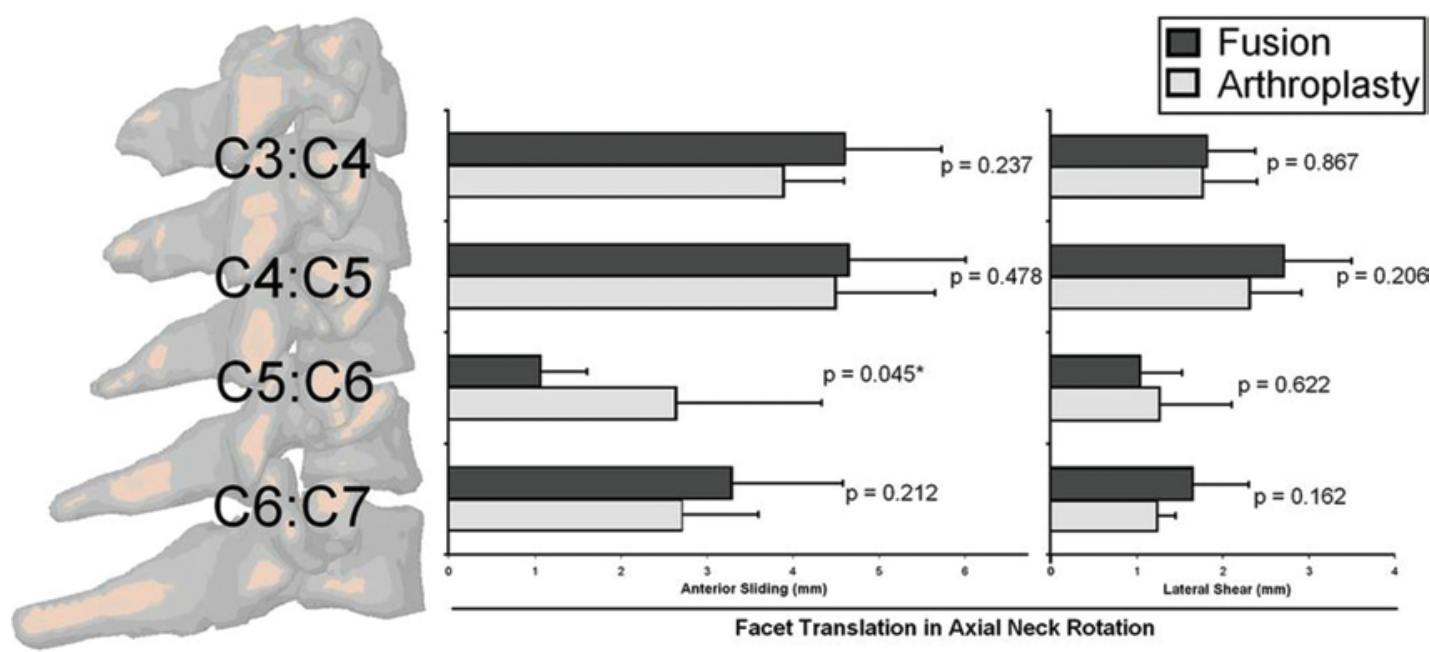

FIG. 9. Facet translation in anterior sliding and lateral shear is shown for the axial neck rotation motion task. Facet translation was greater in the $A D$ group at $C 5-6$ for only anterior sliding. There were no significant differences in facet translation between groups at $\mathrm{C} 3-4, \mathrm{C} 4-5$, and $\mathrm{C} 6-7$.

$(5.7 \pm 0.7 \mathrm{~mm})$ was significantly greater than in the ACDF group $(1.9 \pm 1.6 \mathrm{~mm}, \mathrm{p}<0.001$, Fig. 11$)$. In comparison, there was no significant difference in intervertebral disc height at the nonoperative segments $(p=0.484)$. Isolating by motion segment, differences in intervertebral disc height between the ACDF group and $\mathrm{AD}$ group were most apparent at C6-7 $(3.2 \pm 0.7 \mathrm{~mm}$ vs $3.8 \pm 0.5 \mathrm{~mm}$, $\mathrm{p}=0.107)$ and least apparent at $\mathrm{C} 4-5(3.4 \pm 0.8 \mathrm{~mm}$ vs $3.4 \pm 0.3 \mathrm{~mm}, \mathrm{p}=0.935)$. In the AD group, $\mathrm{C} 5-6$ disc height was significantly greater than the nonoperative segments $(\mathrm{p}<0.01)$. In the fusion group, C5-6 disc height was significantly less than the nonoperative segments ( $\mathrm{p}$ $<0.004)$.

\section{Discussion}

Several studies have compared the biomechanical characteristics of the cervical spine following fusion and arthroplasty. However, these studies are often limited to an assessment of vertebral body kinematics during only neck flexion or extension with lateral radiographs, and therefore can only assess motion in 2 dimensions. Sasso et al. published motion analysis results from their prospective, randomized multicenter trial with the Bryan Cervical Disc (Medtronic Sofamor Danek). ${ }^{63}$ This study benefits from a large sample size with 221 ACDF patients and $242 \mathrm{AD}$ patients. Flexion, extension, and neutral radiographs were used for motion analysis, using sagittal rotation in degrees as its primary end point. This study showed durability of device mobility after 2 years, with a loss of $0.87^{\circ}$ from preoperative values in the $\mathrm{AD}$ group. Measurements of adjacent-segment rotation were also performed with no observed differences between caudal and cranial adjacent-segment motion between $\mathrm{AD}$ and ACDF cohorts.

Lazaro et al. published a study in which 60 patients
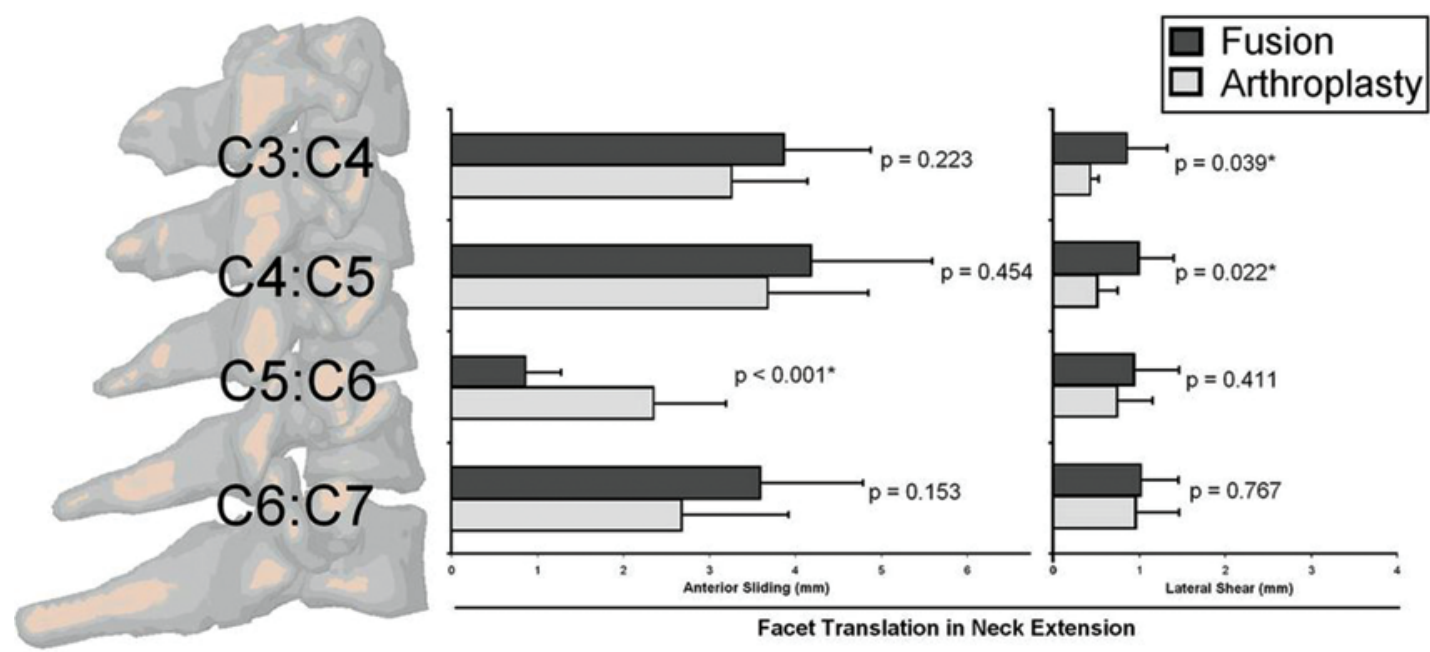

FIG. 10. Facet translation in anterior sliding and lateral shear is shown for the neck extension motion task. Facet translation was greater in the AD group at C5-6 for only anterior sliding, and statistically significantly greater in the ACDF group at C3-4 and $\mathrm{C} 4-5$ for only lateral shear. 


\section{D motion analysis comparing ACDF with an artificial disc}

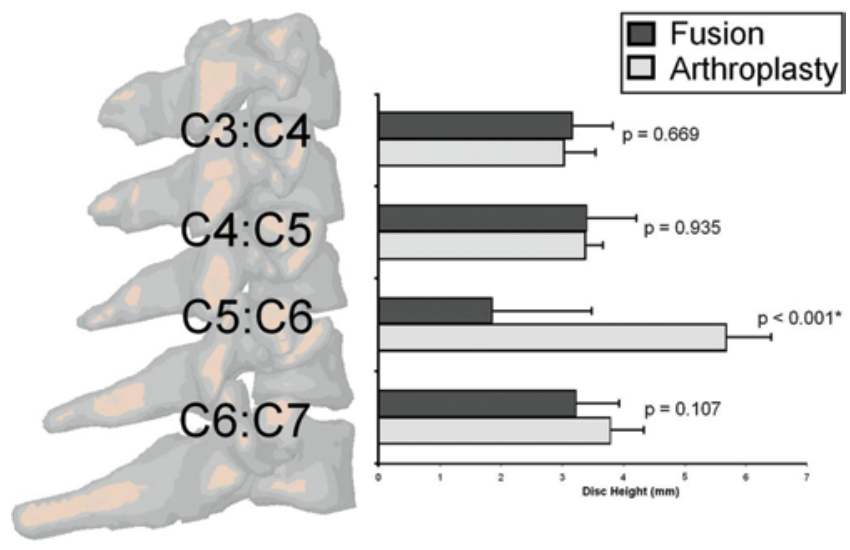

FIG. 11. Intervertebral disc height is shown for each motion segment. The C5-6 disc height in the AD group was significantly greater than in the ACDF group.

were retrospectively analyzed using lateral flexion, extension, and neutral radiographs. ${ }^{43}$ Three devices were included in that study: Bryan Cervical Disc, ProDisc-C (DePuy Synthes, Inc.), and Synergy Cervical Disc (Synergy Disc Replacement, Inc.). The study was concerned primarily with characteristics at the index level, analyzing postoperative range of motion, disc height, sagittal plane translation, angulation, and center of rotation. Of note, the Bryan disc group developed a significant shell kyphosis postoperatively. In addition, both the Bryan and Synergy discs maintained the natural center of rotation while there was a significant anterior shift with the ProDisc-C. This study did not analyze any adjacent-segment parameters.

Kowalczyk et al. published a follow-up study, this time comparing the Prestige LP disc (Medtronic Sofamor Danek) with the Bryan and ProDisc-C implants. ${ }^{39}$ This study also used lateral radiographs and focused on various parameters at the index level including range of motion, disc angle, disc height and translation, and center of rotation. Again, the Bryan disc exhibited significant shell angle kyphosis postoperatively, while the ProDisc-C and Prestige LP discs retained lordosis. There was a loss of disc height following insertion of the Bryan disc. The importance of these findings relates to long-term outcome where kyphosis is associated with an increased incidence of adjacent-segment disease. ${ }^{24}$ However, this study did not examine adjacent-segment parameters.

Anderson et al. ${ }^{1}$ published a systematic review and meta-analysis of 12 studies, including 7 randomized control trials, 4 cohort studies, and 1 case-control study and examined kinematic measurements of adjacent segments after AD replacement and ACDF. End points of interest included adjacent-segment range of motion and centers of rotation after surgery. The authors found no statistical difference between the AD and ACDF cohorts. There was a difference in lordotic angulation of adjacent segments in patients who underwent AD replacement and those who underwent ACDF. However, there was no change in global sagittal alignment (C2-7) between the cohorts at the 2-year follow-up. Again, this study dealt exclusively with 2D parameters in the sagittal plane.

In this study, we conducted a thorough in vivo kine- matic analysis of vertebral rotation and facet translation during both neck extension and axial neck rotation motion activities. To our knowledge, this is the first study that is able to assess vertebral motion in vivo and in 3 dimensions after ACDF or AD replacement. A further distinction of this study is that images were acquired in dynamic conditions during active motion, whereas traditional flexion-extension views are obtained at static positions, although the extent to which static testing is representative of dynamic conditions remains unknown. This research also includes analysis at a more remote motion segment, C3-4, in addition to the cranial and caudal segments adjacent to the index level. The findings from this study provide support for reduced vertebral motion across multiple nonoperative segments in arthroplasty patients when compared with fusion patients.

Although previous studies have shown a postsurgical increase in adjacent-segment motion during neck extension after cervical fusion, ${ }^{3,36}$ there is conflicting evidence when comparing adjacent-segment motion between fusion and arthroplasty subjects. Some studies have reported adjacentsegment motion to be greater in fusion subjects than in arthroplasty subjects, ${ }^{18,45}$ while others have reported no difference. ${ }^{34,36}$ Nonsignificant differences between groups in some instances may be explained by a distribution of motion across several motion segments. Although it has been reported previously that motion lost due to fusion is primarily transferred to the cranial adjacent segment, $3,14,53,59$ we found significant differences in motion at the caudal adjacent segment (C6-7) and a remote segment (C3-4), 2 levels cranial to the operative segment. This is similar to the results reported by Finn et al., where motion was simulated in 6 cadaveric specimens under intact, fusion, and arthroplasty conditions..$^{18}$ The authors reported differences in motion between the fusion and arthroplasty conditions at all nonoperative segments ( 2 adjacent and 2 remote), where significance was seen in all but the caudal segment.

It has also been well documented that C5-6 is typically the most mobile segment of the lower cervical spine during neck flexion-extension, followed by $\mathrm{C} 4-5 .^{12,13,57}$ Vertebral motion at the implanted level of arthroplasty patients has been reported to be restored to preoperative levels.$^{36}$ However, it is unknown how preoperative motion at the implanted level may have been affected by cervical degenerative disc disease, making it challenging to determine the extent to which normal vertebral motion at the implanted level is restored postsurgery. A more appropriate approach may be to compare motion at the implanted level to the adjacent segments within the same subject. Kim et al. found no significant difference in motion between the implanted level and adjacent segments. ${ }^{36}$ Similarly, Finn et al. measured cervical arthroplasty in cadaveric specimens and found no significant difference between vertebral levels in neck extension. ${ }^{18}$ In our investigation, we found C5-6 motion to vary widely among subjects, with C4-5 motion being greater than C5-6 motion in 6 of the 7 subjects, suggesting that cervical arthroplasty may not fully restore vertebral motion at the implanted level. However, our findings do illustrate durability of motion at the index level at a mean of 22 months postoperatively. In addition, this finding is also demon- 


\section{P. McDonald et al.}

strated in 3 dimensions, with motion being preserved during axial neck rotation in addition to cervical extension.

In recent years, articular facet biomechanics has become a topic of interest, ${ }^{29-32,44,52}$ as significant changes in relative facet motion following trauma or surgery have been suggested to induce degenerative changes in the articular cartilage. ${ }^{55,65}$ Although studies have investigated in vivo facet kinematics at the lumbar spine, ${ }^{40,44}$ there are no known in vivo studies that have compared different surgical techniques on facet kinematics in the cervical spine. In our investigation, facet translations were described using local facet coordinate systems defined by facet-based landmarks. ${ }^{40,42,44}$ Facet translation during neck extension was primarily in the direction of AP sliding while a coupled translation of combined AP sliding and ML shear was more evident during axial neck rotation. Generally, there were greater translations at the nonoperative segments in the fusion group. The results of our investigation suggest that there may be some degree of hypermobility at nonoperative segments subsequent to cervical fusion, which has been suggested to result in increased compressive stresses between the articulating surfaces and facilitate cartilage degeneration. ${ }^{11,50}$ Although the inclusion of preoperative data are necessary to determine the extent to which facet joint kinematics are altered due to surgery, the differences between patients undergoing $\mathrm{ACDF}$ and $\mathrm{AD}$ replacement found in our study suggest that more attention should nonetheless be paid to the cervical facet joints when considering surgical treatment.

Despite the aforementioned differences in cervical kinematics observed between our ACDF and AD groups, the fact remains that recently published long-term studies of cervical AD results show fairly equivocal results in developing adjacent-segment pathology. ${ }^{7,8,16}$ This has led some authors to conclude that any degeneration at segments adjacent to a fusion is simply part of the natural history of spondylosis and, by extension, not necessarily an iatrogenic result from fusion. ${ }^{16,49}$ Some authors have advocated a shift in the semantics of adjacent-segment disease to adjacent-segment pathology, using descriptors of radiographic adjacent-segment pathology (RASP) and clinical adjacent-segment pathology (CASP) manifestations. ${ }^{61}$ A recent systematic review analyzed 6 randomized control trials, as well as 5 prospective cohort trials regarding the incidence of CASP and RASP. ${ }^{26}$ The authors concluded that there is no significant difference in development of either CASP or RASP after AD replacement versus ACDF at short- to midterm follow-up. Therefore, if CASP has an equal incidence in both ACDF and AD populations despite observed differences in kinematics between the groups, the etiology of cervical spondylosis may not lie in motion characteristics but perhaps biological characteristics of the intervertebral disc and/ or facet joints instead. Thus far, the causality between motion characteristics and a propensity for degeneration and pathogenesis of clinical symptoms by spondylotic pathology has not been clearly established. One possibility is that motion characteristics may be an observed consequence of degeneration as opposed to a cause and that the true underlying cause is an intrinsic biological defect within the joints of the spine. Regardless, additional lon- gitudinal kinematic data in the same patient populations will prove useful in establishing what role motion plays in cervical degeneration.

There was no significant difference in intervertebral disc height between the ACDF and AD groups, except for at the operative level, where the AD group had significantly greater disc height than the fusion group. Changes in disc height resulting from cervical disc disease or surgical intervention have been suggested as a possible factor contributing to the progression of adjacent-segment degeneration, with a decrease in disc height resulting in increased intradiscal pressure and facet contact force. ${ }^{11,29,50,68}$ In our investigation, C5-6 disc height compared with the nonoperative segments was significantly greater in the AD group and significantly lower in the ACDF group. These findings are in agreement with previous studies. . $^{10,33,54,56,69}$ The evaluation of disc height as normal is typically based on comparing adjacent cranially or caudally located discs, ${ }^{38}$ since the preoperative condition of the disc is often already affected by cervical disc disease. Intrasubject measurements of intervertebral disc height of the lower cervical spine have shown little variation across motion segments, ${ }^{20}$ which suggests that adjacent disc height comparison is a suitable approach for the assessment of intervertebral disc height postsurgery.

\section{Conclusions}

We conducted an in vivo study that compared cervical spine kinematics during both neck extension and axial neck rotation between patients undergoing ACDF and AD replacement. Patients treated with cervical fusion of the C5-6 vertebrae had, generally, greater adjacent-segment vertebral rotation and facet translation than the arthroplasty patients. We also found differences in motion at a remote motion segment, suggesting that motion lost due to fusion may be transferred across more than just the adjacent segments. However, our results also suggest that, while arthroplasty results in decreased adjacent segment motion compared with fusion, arthroplasty may not restore motion at the operative segment, possibly due to changes in disc height or heterotopic ossification. ${ }^{67} \mathrm{We}$ recognize that this study has some weaknesses such as the relatively small sample size and a lack of preoperative data for comparison. Notwithstanding these limitations, the data reported here contribute to our understanding of cervical spine kinematics in patients treated with either ACDF or AD replacement, and provide support for reduced vertebral motion across multiple nonoperative motion segments in patients undergoing cervical arthroplasty when compared with those undergoing cervical fusion. An understanding of cervical spine kinematics following either fusion or arthroplasty is an important step toward understanding the relationship between motion and the progression of adjacent-segment degeneration postsurgery.

\section{Disclosure}

The authors report no conflict of interest concerning the materials or methods used in this study or the findings specified in this paper. 


\section{$3 \mathrm{D}$ motion analysis comparing ACDF with an artificial disc}

Author contributions to the study and manuscript preparation include the following. Conception and design: Chang, Bartol. Acquisition of data: Chang, CP McDonald, M McDonald, Ramo, Bey. Analysis and interpretation of data: all authors. Drafting the article: Chang. Critically revising the article: all authors. Reviewed submitted version of manuscript: all authors. Approved the final version of the manuscript on behalf of all authors: Chang. Study supervision: Bartol.

\section{References}

1. Anderson PA, Sasso RC, Hipp J, Norvell DC, Raich A, Hashimoto R: Kinematics of the cervical adjacent segments after disc arthroplasty compared with anterior discectomy and fusion: a systematic review and meta-analysis. Spine (Phila Pa 1976) 37 (22 Suppl):S85-S95, 2012

2. Aryan HE, Lu DC, Acosta FL Jr, Hartl R, McCormick PW, Ames CP: Bioabsorbable anterior cervical plating: initial multicenter clinical and radiographic experience. Spine (Phila Pa 1976) 32:1084-1088, 2007

3. Baba H, Furusawa N, Imura S, Kawahara N, Tsuchiya H, Tomita K: Late radiographic findings after anterior cervical fusion for spondylotic myeloradiculopathy. Spine (Phila Pa 1976) 18:2167-2173, 1993

4. Beaurain J, Bernard P, Dufour T, Fuentes JM, Hovorka I, Huppert $\mathrm{J}$, et al: Intermediate clinical and radiological results of cervical TDR (Mobi-C) with up to 2 years of follow-up. Eur Spine J 18:841-850, 2009

5. Bey MJ, Zauel R, Brock SK, Tashman S: Validation of a new model-based tracking technique for measuring three-dimensional, in vivo glenohumeral joint kinematics. J Biomech Eng 128:604-609, 2006

6. Bohlman HH, Emery SE, Goodfellow DB, Jones PK: Robinson anterior cervical discectomy and arthrodesis for cervical radiculopathy. Long-term follow-up of one hundred and twenty-two patients. J Bone Joint Surg Am 75:1298-1307, 1993

7. Coric D, Kim PK, Clemente JD, Boltes MO, Nussbaum M, James S: Prospective randomized study of cervical arthroplasty and anterior cervical discectomy and fusion with longterm follow-up: results in 74 patients from a single site. Clinical article. J Neurosurg Spine 18:36-42, 2013

8. Coric D, Nunley PD, Guyer RD, Musante D, Carmody CN, Gordon CR, et al: Prospective, randomized, multicenter study of cervical arthroplasty: 269 patients from the Kineflex|C artificial disc investigational device exemption study with a minimum 2-year follow-up. Clinical article. J Neurosurg Spine 15:348-358, 2011

9. Dennis S, Watkins R, Landaker S, Dillin W, Springer D: Comparison of disc space heights after anterior lumbar interbody fusion. Spine (Phila Pa 1976) 14:876-878, 1989

10. Duggal N, Bertagnoli R, Rabin D, Wharton N, Kowalczyk I: ProDisc-C: an in vivo kinematic study. J Spinal Disord Tech 24:334-339, 2011

11. Dunlop RB, Adams MA, Hutton WC: Disc space narrowing and the lumbar facet joints. J Bone Joint Surg Br 66:706710,1984

12. Dvorak J, Froehlich D, Penning L, Baumgartner H, Panjabi MM: Functional radiographic diagnosis of the cervical spine: flexion/extension. Spine (Phila Pa 1976) 13:748-755, 1988

13. Dvorak J, Panjabi MM, Novotny JE, Antinnes JA: In vivo flexion/extension of the normal cervical spine. J Orthop Res 9:828-834, 1991

14. Eck JC, Humphreys SC, Lim TH, Jeong ST, Kim JG, Hodges $\mathrm{SD}$, et al: Biomechanical study on the effect of cervical spine fusion on adjacent-level intradiscal pressure and segmental motion. Spine (Phila Pa 1976) 27:2431-2434, 2002

15. Elsawaf A, Mastronardi L, Roperto R, Bozzao A, Caroli M, Ferrante L: Effect of cervical dynamics on adjacent segment degeneration after anterior cervical fusion with cages. Neurosurg Rev 32:215-224, 2009

16. Fallah A, Akl EA, Ebrahim S, Ibrahim GM, Mansouri A, Foote CJ, et al: Anterior cervical discectomy with arthroplasty versus arthrodesis for single-level cervical spondylosis: a systematic review and meta-analysis. PLoS ONE 7:e43407, 2012

17. Fernández-Fairen M, Sala P, Dufoo M Jr., Ballester J, Murcia A, Merzthal L: Anterior cervical fusion with tantalum implant: a prospective randomized controlled study. Spine (Phila Pa 1976) 33:465-472, 2008

18. Finn MA, Brodke DS, Daubs M, Patel A, Bachus KN: Local and global subaxial cervical spine biomechanics after singlelevel fusion or cervical arthroplasty. Eur Spine J 18:15201527,2009

19. Fountas KN, Kapsalaki EZ, Nikolakakos LG, Smisson HF, Johnston KW, Grigorian AA, et al: Anterior cervical discectomy and fusion associated complications. Spine (Phila Pa 1976) 32:2310-2317, 2007

20. Frobin W, Leivseth G, Biggemann M, Brinckmann P: Vertebral height, disc height, posteroanterior displacement and dens-atlas gap in the cervical spine: precision measurement protocol and normal data. Clin Biomech (Bristol, Avon) 17: 423-431, 2002

21. Garrido BJ, Taha TA, Sasso RC: Clinical outcomes of Bryan cervical disc arthroplasty a prospective, randomized, controlled, single site trial with 48-month follow-up. J Spinal Disord Tech 23:367-371, 2010

22. Goffin J, Geusens E, Vantomme N, Quintens E, Waerzeggers Y, Depreitere B, et al: Long-term follow-up after interbody fusion of the cervical spine. J Spinal Disord Tech 17:79-85, 2004

23. Gore DR, Sepic SB: Anterior cervical fusion for degenerated or protruded discs. A review of one hundred forty-six patients. Spine (Phila Pa 1976) 9:667-671, 1984

24. Gore DR, Sepic SB, Gardner GM: Roentgenographic findings of the cervical spine in asymptomatic people. Spine (Phila Pa 1976) 11:521-524, 1986

25. Hadjipavlou AG, Tzermiadianos MN, Bogduk N, Zindrick MR: The pathophysiology of disc degeneration: a critical review. J Bone Joint Surg Br 90:1261-1270, 2008

26. Harrod CC, Hilibrand AS, Fischer DJ, Skelly AC: Adjacent segment pathology following cervical motion-sparing procedures or devices compared with fusion surgery: a systematic review. Spine (Phila Pa 1976) 37 (22 Suppl):S96-S112, 2012

27. Hida K, Iwasaki Y, Yano S, Akino M, Seki T: Long-term follow-up results in patients with cervical disk disease treated by cervical anterior fusion using titanium cage implants. Neurol Med Chir (Tokyo) 48:440-446, 2008

28. Hilibrand AS, Carlson GD, Palumbo MA, Jones PK, Bohlman HH: Radiculopathy and myelopathy at segments adjacent to the site of a previous anterior cervical arthrodesis. J Bone Joint Surg Am 81:519-528, 1999

29. Hussain M, Natarajan RN, An HS, Andersson GB: Patterns of height changes in anterior and posterior cervical disc regions affects the contact loading at posterior facets during moderate and severe disc degeneration: a poroelastic C5-C6 finite element model study. Spine (Phila Pa 1976) 35:E873-E881, 2010

30. Jaumard NV, Bauman JA, Weisshaar CL, Guarino BB, Welch WC, Winkelstein BA: Contact pressure in the facet joint during sagittal bending of the cadaveric cervical spine. J Biomech Eng 133:071004, 2011

31. Jaumard NV, Welch WC, Winkelstein BA: Spinal facet joint biomechanics and mechanotransduction in normal, injury and degenerative conditions. J Biomech Eng 133:071010, 2011

32. Jegapragasan M, Cook DJ, Gladowski DA, Kanter AS, Cheng BC: Characterization of articulation of the lumbar facets in 


\section{P. McDonald et al.}

the human cadaveric spine using a facet-based coordinate system. Spine J 11:340-346, 2011

33. Kafchitsas K, Kokkinakis M, Habermann B, Rauschmann M: Effect of lumbar disc replacement on the height of the disc space and the geometry of the facet joints: a cadaver study. $\mathbf{J}$ Bone Joint Surg Br 92:595-601, 2010

34. Kelly MP, Mok JM, Frisch RF, Tay BK: Adjacent segment motion after anterior cervical discectomy and fusion versus Prodisc-C cervical total disk arthroplasty: analysis from a randomized, controlled trial. Spine (Phila Pa 1976) 36:11711179,2011

35. Kesman T, Murrey D, Darden B: Single-center results at 7 years of prospective, randomized ProDisc-C total disc arthroplasty versus anterior cervical discectomy and fusion for treatment of one level symptomatic cervical disc disease. Evid Based Spine Care J 3:61-62, 2012

36. Kim SW, Limson MA, Kim SB, Arbatin JJ, Chang KY, Park MS, et al: Comparison of radiographic changes after ACDF versus Bryan disc arthroplasty in single and bi-level cases. Eur Spine J 18:218-231, 2009

37. Koller H, Hempfing A, Ferraris L, Maier O, Hitzl W, MetzStavenhagen P: 4- and 5-level anterior fusions of the cervical spine: review of literature and clinical results. Eur Spine J 16:2055-2071, 2007

38. Kolstad F, Myhr G, Kvistad KA, Nygaard OP, Leivseth G: Degeneration and height of cervical discs classified from MRI compared with precise height measurements from radiographs. Eur J Radiol 55:415-420, 2005

39. Kowalczyk I, Lazaro BC, Fink M, Rabin D, Duggal N: Analysis of in vivo kinematics of 3 different cervical devices: Bryan disc, ProDisc-C, and Prestige LP disc. Clinical article. J Neurosurg Spine 15:630-635, 2011

40. Kozanek M, Wang S, Passias PG, Xia Q, Li G, Bono CM, et al: Range of motion and orientation of the lumbar facet joints in vivo. Spine (Phila Pa 1976) 34:E689-E696, 2009

41. Kulkarni V, Rajshekhar V, Raghuram L: Accelerated spondylotic changes adjacent to the fused segment following central cervical corpectomy: magnetic resonance imaging study evidence. J Neurosurg 100 (1 Suppl Spine):2-6, 2004

42. Kunkel ME, Schmidt H, Wilke HJ: Prediction of the human thoracic and lumbar articular facet joint morphometry from radiographic images. J Anat 218:191-201, 2011

43. Lazaro BC, Yucesoy K, Yuksel KZ, Kowalczyk I, Rabin D, Fink M, et al: Effect of arthroplasty design on cervical spine kinematics: analysis of the Bryan Disc, ProDisc-C, and Synergy disc. Neurosurg Focus 28(6):E6, 2010

44. Li W, Wang S, Xia Q, Passias P, Kozanek M, Wood K, et al: Lumbar facet joint motion in patients with degenerative disc disease at affected and adjacent levels: an in vivo biomechanical study. Spine (Phila Pa 1976) 36:E629-E637, 2011

45. Liu F, Cheng J, Komistek RD, Mahfouz MR, Sharma A: In vivo evaluation of dynamic characteristics of the normal, fused, and disc replacement cervical spines. Spine (Phila Pa 1976) 32:2578-2584, 2007

46. Matsunaga S, Kabayama S, Yamamoto T, Yone K, Sakou T, Nakanishi K: Strain on intervertebral discs after anterior cervical decompression and fusion. Spine (Phila Pa 1976) 24:670-675, 1999

47. McDonald CP, Bachison CC, Chang V, Bartol SW, Bey MJ: Three-dimensional dynamic in vivo motion of the cervical spine: assessment of measurement accuracy and preliminary findings. Spine J 10:497-504, 2010

48. Mummaneni PV, Burkus JK, Haid RW, Traynelis VC, Zdeblick TA: Clinical and radiographic analysis of cervical disc arthroplasty compared with allograft fusion: a randomized controlled clinical trial. J Neurosurg Spine 6:198-209, 2007

49. Nunley PD, Jawahar A, Kerr EJ III, Gordon CJ, Cavanaugh DA, Birdsong EM, et al: Factors affecting the incidence of symptomatic adjacent-level disease in cervical spine after to- tal disc arthroplasty: 2- to 4-year follow-up of 3 prospective randomized trials. Spine (Phila Pa 1976) 37:445-451, 2012

50. Panjabi MM, Krag MH, Chung TQ: Effects of disc injury on mechanical behavior of the human spine. Spine (Phila Pa 1976) 9:707-713, 1984

51. Panjabi MM, Krag MH, Goel VK: A technique for measurement and description of three-dimensional six degree-of-freedom motion of a body joint with an application to the human spine. J Biomech 14:447-460, 1981

52. Panjabi MM, Simpson AK, Ivancic PC, Pearson AM, Tominaga Y, Yue JJ: Cervical facet joint kinematics during bilateral facet dislocation. Eur Spine J 16:1680-1688, 2007

53. Park DK, Lin EL, Phillips FM: Index and adjacent level kinematics after cervical disc replacement and anterior fusion: in vivo quantitative radiographic analysis. Spine (Phila Pa 1976) 36:721-730, 2011

54. Park JY, Chin DK, Cho YE: Accelerated L5-S1 segment degeneration after spinal fusion on and above L4-5: minimum 4-year follow-up results. J Korean Neurosurg Soc 45:81-84, 2009

55. Pearson AM, Ivancic PC, Ito S, Panjabi MM: Facet joint kinematics and injury mechanisms during simulated whiplash. Spine (Phila Pa 1976) 29:390-397, 2004

56. Peng CW, Quirno M, Bendo JA, Spivak JM, Goldstein JA: Effect of intervertebral disc height on postoperative motion and clinical outcomes after Prodisc-C cervical disc replacement. Spine J 9:551-555, 2009 (Erratum in Spine J 10:A8, 2010)

57. Penning L: Normal movements of the cervical spine. AJR Am J Roentgenol 130:317-326, 1978

58. Powell JW, Sasso RC, Metcalf NH, Anderson PA, Hipp JA: Quality of spinal motion with cervical disk arthroplasty: computer-aided radiographic analysis. J Spinal Disord Tech 23:89-95, 2010

59. Ragab AA, Escarcega AJ, Zdeblick TA: A quantitative analysis of strain at adjacent segments after segmental immobilization of the cervical spine. J Spinal Disord Tech 19:407-410, 2006

60. Rajaee SS, Bae HW, Kanim LE, Delamarter RB: Spinal fusion in the United States: analysis of trends from 1998 to 2008. Spine (Phila Pa 1976) 37:67-76, 2012

61. Riew KD, Norvell DC, Chapman JR, Skelly AC, Dettori JR: Introduction/Summary statement: adjacent segment pathology. Spine (Phila Pa 1976) 37 (22 Suppl):S1-S7, 2012

62. Robertson JT, Papadopoulos SM, Traynelis VC: Assessment of adjacent-segment disease in patients treated with cervical fusion or arthroplasty: a prospective 2-year study. J Neurosurg Spine 3:417-423, 2005

63. Sasso RC, Best NM, Metcalf NH, Anderson PA: Motion analysis of Bryan cervical disc arthroplasty versus anterior discectomy and fusion: results from a prospective, randomized, multicenter, clinical trial. J Spinal Disord Tech 21:393-399, 2008

64. Sasso RC, Smucker JD, Hacker RJ, Heller JG: Clinical outcomes of BRYAN cervical disc arthroplasty: a prospective, randomized, controlled, multicenter trial with 24-month follow-up. J Spinal Disord Tech 20:481-491, 2007

65. Stemper BD, Yoganandan N, Gennarelli TA, Pintar FA: Localized cervical facet joint kinematics under physiological and whiplash loading. J Neurosurg Spine 3:471-476, 2005

66. Stokes IA: Three-dimensional terminology of spinal deformity. A report presented to the Scoliosis Research Society by the Scoliosis Research Society Working Group on 3-D terminology of spinal deformity. Spine (Phila Pa 1976) 19:236-248, 1994

67. Suchomel P, Jurák L, Benes V III, Brabec R, Bradác O, Elgawhary S: Clinical results and development of heterotopic ossification in total cervical disc replacement during a 4-year follow-up. Eur Spine J 19:307-315, 2010

68. Tang S, Meng X: Does disc space height of fused segment 


\section{D motion analysis comparing ACDF with an artificial disc}

affect adjacent degeneration in ALIF? A finite element study. Turk Neurosurg 21:296-303, 2011

69. Türeyen K: Disc height loss after anterior cervical microdiscectomy with titanium intervertebral cage fusion. Acta Neurochir (Wien) 145:565-570, 2003

70. Upadhyaya CD, Wu JC, Trost G, Haid RW, Traynelis VC, Tay B, et al: Analysis of the three United States Food and Drug Administration investigational device exemption cervical arthroplasty trials. Clinical article. J Neurosurg Spine 16: 216-228, 2012

71. Walraevens J, Demaerel P, Suetens P, Van Calenbergh F, van Loon J, Vander Sloten J, et al: Longitudinal prospective longterm radiographic follow-up after treatment of single-level cervical disk disease with the Bryan Cervical Disc. Neurosurgery 67:679-687, 2010

72. Wigfield C, Gill S, Nelson R, Langdon I, Metcalf N, Robertson J: Influence of an artificial cervical joint compared with fusion on adjacent-level motion in the treatment of degenerative cervical disc disease. J Neurosurg 96 (1 Suppl):17-21, 2002

73. Williams JL, Allen MB Jr, Harkess JW: Late results of cervical discectomy and interbody fusion: some factors influencing the results. J Bone Joint Surg Am 50:277-286, 1968

Manuscript submitted April 25, 2013.

Accepted November 19, 2013.

Please include this information when citing this paper: published online December 20, 2013; DOI: 10.3171/2013.11.SPINE13392.

Address correspondence to: Victor Chang, M.D., Department of Neurosurgery, Henry Ford Health System, 2799 W. Grand Blvd., Detroit, MI 48202. email: vicchang@gmail.com. 